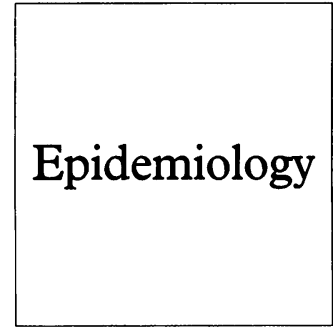

\author{
Masatoshi Tanaka, Hiroshi Nakayama, Misao Sakumoto, Tetsuro Matsumoto, \\ Kohei Akazawa, Joichi Kumazawa
}

\title{
Trends in sexually transmitted diseases and condom use patterns among commercial sex workers in Fukuoka City, Japan 1990-93
} tohet Akazawa, Joichi Kumazawa

Objective: To investigate trends in sexually transmitted diseases (STDs) among female commercial sex workers and in their condom use patterns during the period from 1990 to 1993 in Fukuoka, Japan.

Methods: The study group consisted of a total of 824 commercial sex workers who attended an STD clinic to undergo screening for STDs including chlamydia, gonorrhoea, syphilis, hepatitis B and HIV-1 infection during the period from 1990 to 1993. For detection of Chlamydia trachomatis and Neisseria gonorrhoeae, endocervical smear specimens were taken from the women. Blood samples were obtained for serological diagnosis of syphilis, hepatitis B and HIV-1. Commercial sex workers who visited the clinic during the period from November to December of 1993 were interviewed concerning past (1990 and 1991) and recent (1992 and 1993) condom use patterns. Results: The annual detection rates of $C$ trachomatis and $N$ gonorrhoeae declined significantly from $16.3 \%$ in 1990 to $12.2 \%$ in $1993(\mathrm{P}<0.0001)$ and from $1.5 \%$ in 1990 to $0.8 \%$ in 1993 $(\mathbf{P}=0.0096)$, respectively. There was a remarkable reduction in the annual syphilis infection rate, from $7.5 \%$ in 1990 to $0.5 \%$ in $1993(\mathrm{P}=0.0011)$. The positive rate for the hepatitis $\mathrm{B}$ surface antigen in the women ranged from only $0.6 \%$ to $1.9 \%$ and none were found to be positive for HIV-1 during the 4-year period. During the same period, there was a significant increase in the proportion of commercial sex workers always using condoms from $6.3 \%$ in $1990-91$ to $25.3 \%$ in 1992-93 ( $P=0.0023)$.

Conclusion: The prevalences of chlamydia, gonorrhoea, and syphilis infections decreased significantly among commercial sex workers in Fukuoka from 1990 through 1993, and no commercial sex workers were HIV-1 seropositive. The reductions in the prevalence of major STDs may be related to the increased use of condoms.

(Genitourin Med 1996;72:358-361)

Keywords: Commercial sex worker, STD, condom, trend

\section{Introduction}

In Fukuoka city, as well as in other foreign cities, female commercial sex workers (prostitutes) providing sexual services for money are a major reservoir of sexually transmitted diseases (STDs). For instance, approximately $55 \%$ of men with chlamydia urethritis and $65 \%$ of men with gonorrhoea who attended an STD clinic in Fukuoka from 1990 to 1991 were infected by female commercial sex workers. ${ }^{1}$ Therefore, many of the commercial sex workers seem to have chlamydia and/or gonorrhoea. Furthermore, it is suspected that the prevalence in STDs other than chlamydia and gonorrhoea, such as syphilis, may be high in these women. In addition, the potential spread of HIV-1 infection may be occurring among these women, because the number of HIV-1 infections transmitted through heterosexual contact has been increasing rapidly since 1991 in Japan. ${ }^{2}$ Information about STD trends among commercial sex workers and their condom use pattern would thus be useful for devising methods of controlling STDs.

Until recently, epidemiological studies of STDs including HIV-1 infection among Japanese female commercial sex workers and their pattern of condom use have been rare. Therefore, in this investigation, we collected longitudinal data concerning the prevalence of chlamydia, gonorrhoea, syphilis, hepatitis B, and HIV-1 infections among commercial sex workers and their condom use patterns during the period from 1990 to 1993 in Fukuoka.

\section{Materials and methods \\ Study population}

The study group consisted of a total of 824 Japanese commercial sex workers who attended an STD clinic in Fukuoka during the period from 1990 to 1993 in order to undergo screening for STDs including chlamydia, gonorrhoea, syphilis, hepatitis B and HIV-1 infection. The majority were asymptomatic and voluntarily sought STD check-ups. Nearly all the commercial sex workers engaged in oral and vaginal sex with their clients. The average age of the commercial sex workers was 29.4 years, range 18 to 57 years. The majority were aged between 20 and 29 years. The annual number of women who attended and were examined for chlamydia, gonorrhoea, syphilis, hepatitis B and HIV-1 infections and the annual number of tests performed for the diagnosis of STDs are summarised in table 1. Endocervical smear specimens for the detection of Chlamydia trachomatis and Neisseria gonorrhoeae and blood samples for serological diagnosis of syphilis, hepatitis B, and HIV-1 
Table 1 Number of commercial sex workers examined and number of screening tests performed for sexually transmitted diseases (1990-93)

\begin{tabular}{|c|c|c|c|c|c|c|}
\hline \multirow[b]{2}{*}{ Year } & \multirow{2}{*}{$\begin{array}{l}\text { Total } \\
\text { subjects }\end{array}$} & \multicolumn{5}{|c|}{ Average no. tests per woman (no. tests/no. women) } \\
\hline & & Chlamydia & Gonorrhoea & Syphilis & Hepatitis $B$ virus & $H I V-1$ \\
\hline $\begin{array}{l}1990 \\
1991 \\
1992 \\
1993 \\
\text { Total }\end{array}$ & $\begin{array}{l}220 \\
203 \\
211 \\
190 \\
824\end{array}$ & $\begin{array}{l}7 \cdot 1(1184 / 167) \\
7 \cdot 7(1374 / 178) \\
9 \cdot 0(1683 / 187) \\
9 \cdot 8(1756 / 179) \\
8 \cdot 4(5997 / 711)\end{array}$ & $\begin{array}{l}11 \cdot 4(2410 / 212) \\
12 \cdot 8(2494 / 195) \\
12 \cdot 2(2533 / 207) \\
13 \cdot 2(2418 / 183) \\
12 \cdot 4(9855 / 797)\end{array}$ & $\begin{array}{l}7 \cdot 6(1623 / 214) \\
8 \cdot 8(1740 / 198) \\
8 \cdot 0(1646 / 205) \\
8 \cdot 5(1600 / 188) \\
8 \cdot 2(6609 / 805)\end{array}$ & $\begin{array}{l}6 \cdot 1(953 / 156) \\
7 \cdot 2(1123 / 156) \\
6 \cdot 8(1123 / 164) \\
6 \cdot 7(1086 / 161) \\
6 \cdot 7(4285 / 637)\end{array}$ & $\begin{array}{l}6.3(1290 / 206) \\
7.7(1521 / 197) \\
7.5(1514 / 202) \\
7.8(1459 / 186) \\
7.3(5784 / 791)\end{array}$ \\
\hline
\end{tabular}

Table 2 Chlamydia infection, gonorrhoea, and syphilis rates among commercial sex workers (1990-93)

\begin{tabular}{|c|c|c|c|c|c|}
\hline & \multicolumn{2}{|c|}{ Chlamydia (total) } & \multicolumn{2}{|c|}{ Gonorrhoea (total) } & \multirow{2}{*}{$\frac{\text { Syphilis (Total) }}{\text { No. women } \%}$} \\
\hline & No. tests \% & No. women \% & No. tests \% & No. women $\%$ & \\
\hline $\begin{array}{l}1990 \\
1991 \\
1992 \\
1993\end{array}$ & $\begin{array}{l}16 \cdot 3(1184) \\
16 \cdot 2(1374) \\
13 \cdot 5(1683) \\
12 \cdot 2(1765)\end{array}$ & $\begin{array}{l}58 \cdot 9(167) \\
62 \cdot 9(178) \\
56 \cdot 7(187) \\
55 \cdot 3(179)\end{array}$ & $\begin{array}{l}1.5(2410) \\
1.6(2494) \\
1.1(2533) \\
0.8(2418)\end{array}$ & $\begin{array}{r}13 \cdot 2(212) \\
13 \cdot 3(195) \\
10 \cdot 6(207) \\
8 \cdot 7(183)\end{array}$ & $\begin{array}{l}7 \cdot 5(214) \\
5 \cdot 1(198) \\
2 \cdot 0(205) \\
0.5(188)\end{array}$ \\
\hline
\end{tabular}

infection were collected from the women. If STDs were diagnosed in a commercial sex worker, the woman was treated immediately. Seventy-nine commercial sex workers who visited the clinic during the period from November to December in 1993 were interviewed regarding past (1990 to 1991) and recent (1992 to 1993) condom use patterns. Condom use patterns were divided into three categories (always used condom [100\%], sometimes used condom [1 99\%], never used condom [0\%]) and differences in the proportion of each category between the 1990-91 period and the 1992-93 period were compared.

\section{Laboratory examination}

For the detection of the $C$ trachomatis antigen in endocervical smears, an amplified enzymeimmunoassay kit (IDEIA Chlamydia test, Dako, UK) was used. The screening for gonorrhoea was performed by microscopical examination of gram-stained smears. In cases showing gram-negative diplococci, the gonococcal antigen was confirmed additionally using a commercial enzymeimmunoassay kit (Gonozyme, Abbott, USA). The serological tests used were: for syphilis, the venereal disease research laboratory (VDRL) test and Treponema pallidum haemagglutination test (TPHA, Fujirebio, Japan) which was performed on sera positive by the VDRL test for specific testing; for hepatitis B virus surface antigen (HBs), an enzymeimmunoassay kit (Auszyme, Abbott, USA); for HIV-1 antibody, an enzymeimmunoassay kit (HTLV-III EIA, Abbott, USA).

\section{Statistical analysis}

Tests for statistical significance were performed with BMDP Statistical Programs (BMDP Statistical Software, Inc., Los Angeles, CA) using chi square test, Cochran's test of linear trend, and Kruskal-Wallis test, as appropriate.

\section{Results}

Chlamydia infection

During the period from 1990 to 1993 , a total of 5997 smear specimens obtained from 711 commercial sex workers were tested for chlamydia infection (table 1 ). The $C$ trachomatis detection rate in these women, which was calculated by dividing the number of tests positive for chlamydia by the total number of tests conducted each year, declined significantly from $16.3 \%(193 / 1184)$ in 1990 to $12 \cdot 2 \%$ $(214 / 1765)$ in 1993 (table 2, Cochran's test of linear trend [linear trend]: $\mathrm{P}<0.0001)$. The annual chlamydia infection rate among commercial sex workers, which was calculated by dividing the number of women having one or more episodes of chlamydia infection by the total number of women examined each year, also decreased slightly from $58.9 \%(97 / 167)$ in 1990 to $55 \cdot 3 \%(99 / 179)$ in 1993 (table 2). However, this decrease was not significant (linear trend: $P=0.3675$ ).

Table 3 shows the annual frequency of chlamydia infections among commercial sex workers who underwent chlamydia screening more than 10 times a year. Approximately 70 to $80 \%$ of the women were infected with $C$ trachomatis more than once in each year. Moreover, approximately $50 \%$ of the women had more than two episodes of chlamydia infection annually. There were no significant annual change in the frequency of chlamydia infection among these women (Kruskal-Wallis test: $\mathrm{P}=0.9344$ ).

\section{Gonorrhoea}

During the period from 1990 to 1993 , a total of 9855 smear specimens obtained from 797 commercial sex workers were screened for gonorrhoea (table 1). The detection rate of $N$ gonorrhoeae from the endocervical smears, which was calculated by dividing the number of tests positive for $N$ gonorrhoeae by the total number of tests conducted each year,

Table 3 Frequency of chlamydia infections among commercial sex workers receiving chlamydia screening more than 10 times per year (1990-93)

\begin{tabular}{|c|c|c|c|c|}
\hline \multirow[b]{2}{*}{ Year } & \multicolumn{4}{|c|}{ Frequency of infection (per year) } \\
\hline & $0(\%)$ & $1(\%)$ & 2 or $3(\%)$ & $4 \leqslant(\%)$ \\
\hline $\begin{array}{l}1990(n=45) \\
1991(n=61) \\
1992(n=74) \\
1993(n=74)\end{array}$ & $\begin{array}{l}24 \\
21 \\
23 \\
30\end{array}$ & $\begin{array}{l}27 \\
25 \\
22 \\
16\end{array}$ & $\begin{array}{l}38 \\
39 \\
42 \\
35\end{array}$ & $\begin{array}{l}11 \\
15 \\
14 \\
19\end{array}$ \\
\hline
\end{tabular}


Table 4 Condom use patterns among commercial sex workers (1990-93)

\begin{tabular}{lcll}
\hline \multicolumn{4}{c}{ Condom use } \\
\cline { 2 - 4 } Year & $\begin{array}{l}\text { Always } \\
(\%)\end{array}$ & $\begin{array}{l}\text { Sometimes } \\
(\%)\end{array}$ & $\begin{array}{l}\text { Never } \\
(\%)\end{array}$ \\
\hline $1990-1992\left(\mathrm{n}=79^{\star}\right)$ & $6 \cdot 3$ & $48 \cdot 1$ & $45 \cdot 6$ \\
$1992-1993(\mathrm{n}=79)$ & 25.3 & $69 \cdot 6$ & $5 \cdot 1$ \\
\hline
\end{tabular}

* Seventy-nine commercial sex workers were interviewed concerning condom use during the $1990-91$ and $1992-93$ periods.

decreased significantly from $1 \cdot 5 \%(36 / 2410)$ in 1990 to $0 \cdot 8 \%(19 / 2418)$ in 1993 (table 2, linear trend: $P=0.0096)$. The annual gonorrhoea infection rate among commercial sex workers, which was calculated by dividing the number of women having one or more episodes of gonorrhoea by the total number of women examined each year, also declined gradually from $13.2 \%(28 / 212)$ in 1990 to $8.7 \%(16 / 183)$ in 1993 (table 2). However, this decline was not significant (linear trend: $P=0 \cdot 1186)$.

Syphilis, hepatitis $B$ virus, and HIV-1 infections Between 1990 and 1993, a remarkable decrease was found in the syphilis infection rate among commercial sex workers in Fukuoka, from $7.5 \%(16 / 214)$ in 1990 to $0.5 \%(1 / 186)$ in 1993 (table 2 , linear trend: $P=$ $0.0011)$. The hepatitis $B$ virus infection rate in these women ranged from only $0.6 \%$ to $1.9 \%$ during the same period. During the period from 1990 to 1993, a total of 5784 blood samples collected from the 791 commercial sex workers were tested for HIV-1 antibody. None however were found to be seropositive for HIV-1.

\section{Condom use}

Table 4 shows the condom use patterns of 79 commercial sex workers who were interviewed concerning their condom use patterns during the 1990-91 period and the 1992-93 period. During the study period, there was a significant increase in the proportion of commercial sex workers always using condoms from $6.3 \%$ $(5 / 79)$ in 1990 to $25.3 \%(20 / 79)$ in 1993 (chi square: $P=0.0023$ ) and also a significant increase in the proportion of commercial sex workers sometimes using condoms from $48 \cdot 1 \%(38 / 79)$ in 1990 to $69.6 \%(55 / 79)$ in 1993 (chi square: $P=0.0097$ ). In contrast, the proportion of commercial sex workers never using condoms declined dramatically from $45 \cdot 6 \%(36 / 79)$ in 1990 to $5 \cdot 1 \%(4 / 79)$ in 1993 (chi square: $\mathrm{P}<0.0001$ ).

\section{Discussion}

It is well known that commercial sex workers play an important role in the spread of STDs, not only in developing countries but also in developed nations, and the epidemiology of STDs in the women has been reported from several countries. ${ }^{3-10}$ However, less is known about the prevalence of STDs including HIV-1 infection among Japanese female commercial sex workers and their patterns of condom use. In this study, we investigated trends in major
STDs including chlamydia, gonorrhoea, syphilis, hepatitis $B$ and HIV-1 infections among commercial sex workers and in their condom use patterns in Fukuoka during the period from 1990 through 1993.

The annual detection rates of $C$ trachomatis and $N$ gonorrhoeae among commercial sex workers declined significantly during the 4year period. Moreover, the syphilis infection rate in these women also decreased remarkably. Recently, decreased prevalences of major STDs in commercial sex workers have also been reported from several western countries. In Austria (Vienna), the $C$ trachomatis infection rate in registered prostitutes decreased from $20.4 \%$ in 1980 to $2 \cdot 2 \%$ in 1989 and also decreased from $31.4 \%$ to $10.9 \%$ in nonregistered prostitutes. ${ }^{7}$ The gonococcal detection rate was only $0.5 \%$ in registered and $6.9 \%$ in non-registered prostitutes. ${ }^{7}$ In France (Strasbourg), it was reported that syphilis and gonorrhoea have only exceptionally been isolated in prostitutes since $1987 .^{8}$ Declines in gonorrhoea rates have also been reported among prostitutes in Australia (Sydney) and the Netherlands. ${ }^{910}$ These reductions in the prevalences of major STDs among commercial sex workers in Japan and western countries are probably related to changes in their sexual behaviour owing to the fear of AIDS, specifically to the increased frequency of condom use.

However, the chlamydia infection rate of $55.3 \%$ in 1993 seems to still be high, although the detection rate and the rate of chlamydia infection in commercial sex workers declined annually from 1990 to 1993 . In addition, a persistently high $C$ trachomatis infection rate was recognised in a portion of the commercial sex workers. Approximately 70 to $80 \%$ of the commercial sex workers who underwent chlamydia screening more than 10 times a year were infected with $C$ trachomatis more than once in each year (table 3). Moreover, approximately $50 \%$ of these women had more than two episodes of chlamydia infection. It is postulated that those women who suffer from chlamydia infection rather frequently continue engaging in higher risk sexual behaviours.

In this study, gonococcal diagnosis was performed by microscopic examination of gramstained smears which is less sensitive than cultural recovery of gonococci in women. A recent study demonstrated that the sensitivity of staining methods half that of culture methods in the diagnosis of gonorrhoea in female prostitutes. ${ }^{7}$ However, the advantage of microscopic examination which is easy and fast is the possibility of treating the patient at the first visit in the event of positive findings. The detection rate of gonococci ranged from only $0.8 \%$ to $1.6 \%$ and was 10 to 15 -fold less than that of $C$ trachomatis, which ranged from $12 \cdot 2 \%$ to $16 \cdot 3 \%$ during the period from 1990 to 1993 . Thus, although the actual prevalence of $N$ gonorrhoeae may be higher than the $0.8 \%$ to $1.6 \%$ found in the present investigation, it is clear that the prevalence of gonorrhoea is lower than that of chlamydia infection in the women studied. In our previous study, a 
higher prevalence of chlamydia infection was also found in male as well as in female STD patients, as compared with that of gonorrhoea. ${ }^{1}$

Until recently, HIV infections in Japan have been detected largely in haemophiliacs and homosexual men with overseas sexual contact. However, HIV heterosexually transmitted has been increasing steadily in Japan since $1991 .^{2}$ The spread of HIV-1 infection in commercial sex workers, who are a high risk group as a reservoir for STDs including HIV-1 infection, may underlie the explosive epidemic of HIV-1 infection in the general population. Fortunately, none of the commercial sex workers were seropositive for HIV-1 during this 4year period, although we performed tests to detect anti-HIV-1 antibody in a total of 5784 blood samples obtained from 791 women.

Among the 79 commercial sex workers who were interviewed concerning their condom use patterns, a significant increase in the frequency of condom use was observed in the 1992-93 period, as compared with in the 1990-91 period. The proportion of commercial sex workers who always used condoms in 1992-93 was 4-fold higher than that in 1990-91. In contrast, the proportion of women who never used condoms in 1992-93 was 9-fold less than that in 1990-91. The increased use of condoms among the commercial sex workers is probably due to the fear of AIDS. The increased use of condoms is probably one of the main causes of the reductions in chlamydia, gonorrhoea and syphilis infections among these women.

In summary, the prevalences of major STDs including chlamydia, gonorrhoea, and syphilis declined among commercial sex workers in Fukuoka in 1993. No seropositive commercial sex workers were found. A significant increase in condom use among the women was observed in 1992-93, as compared with in 1990-91. The reductions in the prevalences of major STDs seemed to reflect the increased use of condoms among these women. In a portion of the commercial sex workers, however, the $C$ trachomatis infection rate is still high. It is important to continue close monitoring of the prevalences of STDs including HIV-1 infection and the condom use patterns of these women.

1 Tanaka $M$. Recent trends of sexually transmitted diseases in Fukuoka city. Jpn Arch STD 1993;4:39-46.

2 Miyazaki $M$, Naemura $M$. Epidemiological characteristics on human immunodeficiency virus infection and acquired immunodeficiency syndrome in Japan. Int $f$ STD AIDS 1994;5:273-8.

3 Ramachandran S, Ngeow YF. The prevalence of sexually transmitted diseases among prostitutes in Malaysia. Genitourin Med 1990;66:334-6.

4 Samra Z, Dan M, Segev S, Fintsi Y, Bar-Shany S, Weinberg $M$. Prevalence of sexually transmitted pathogens among women attending a methadone clinic in Israel. Genitourin Med 1991;67:133-6.

5 Kaptue L, Zekeng L, Djoumessi S, Monny-Lobe M, Nichols D, Debuysscher R. HIV and chlamydia infecNichols D, Debuysscher R. HIV and chlamydia infections among prostitutes in

6 Cameron DW, Ngugi EN, Ronald AR, Simonsen JN, Braddick $M$, Bosire $M$. Condom use prevents genital ulcers in women working as prostitutes. Influence of human immunodeficiency virus infection. Sex Transm Dis 1991;18:188-91.

7 Stary A, Kopp W, Söltz-Szöts J. Medical health care for Viennese prostitutes. Sex Transm Dis 1991;18:159-65.

8 Cribier B, Asch PH, Tardieu JC. Declining rates of gonorrhoea and syphilis in Strasbourg, France: a 20 -year study. Genitourin Med 1994;70:273-7.

9 Philpot CR, Harcourt CL, Edwards JM. A survey of female prostitutes at risk of HIV infection and other sexually prostitutes at risk of HIV infection and other sexually
transmissible diseases. Genitourin Med 1991;67:384-8.

10 Treurniet HF, Davidse W. Sexually transmitted diseases reported by STD services in the Netherlands, 1984-90. Genitourin Med 1993;69:434-8. 